\title{
KORELASI AQIDAH AKHLAK DENGAN JIWA NASIONALISME SISWA MTS (Studi kasus di MTS Ikhsaniyah Banyumudal Moga)
}

\author{
Oleh. \\ Umami dan Muhlisin \\ IAIN Pekalongan \\ e-mail: Rizalabu084@gmail.com
}

\begin{abstract}
Aqidah Akhlak has a contribution in motivating students to learn and practice their creeds in the form of habituation to do good morals and avoid morals. This type of research is in the form of field research using a quantitative approach. This research data collection technique uses a questionnaire and documentation method. Data analysis techniques using Product moment correlation. The results of this study indicate that the learning of Aqeedah morals in MTs Ikhsaniyah Banyumudal Moga is included in the medium category with an average value of 50.6. This value is in the intervals of 45.2-56. While the variable of the Nationalism Spirit of MTs Ikhsaniyah Banyumudal Students Moga is included in the medium category, where the calculation results obtained an average value of the Soul of Nationalism of 58.03. This value is in the interval 53.74-63.34. The results of the calculation of the relationship between Aqeedah Moral Learning with the Soul of Nationalism Students of MTs Ikhsaniyah Banyumudal Moga obtained a correlation coefficient of 0.428. In addition, also obtained results that the significance value of 0,000. If the significance value is compared with the significance level ( $\alpha)$, the significance value is obtained $=0,000<\alpha=0.05$. Thus it can be concluded that the null hypothesis $(\mathrm{Ho})$ is rejected and the alternative hypothesis ( $\mathrm{Ha}$ ) is accepted. It can be said that there is a significant positive relationship between Aqeedah Moral Learning and the Soul of Student Nationalism. The correlation coefficient of 0.4288 is at intervals of 0.40-0.599 so based on the table the level of correlation and the strength of the relationship can be concluded that the relationship between morality learning with the Soul of Nationalism Students have a strong relationship.
\end{abstract}

Keywords: Learning Aqidah Akhlak, the Soul of Student Nationalism

\begin{abstract}
Abstrak
Aqidah Akhlak memiliki kontribusi dalam memotivasi siswa untuk belajar dan mempraktikkan kepercayaan mereka dalam bentuk pembiasaan untuk melakukan moral yang baik dan menghindari


moral. Jenis penelitian ini adalah dalam bentuk penelitian lapangan menggunakan pendekatan kuantitatif. Teknik pengumpulan data penelitian ini menggunakan metode angket dan dokumentasi. Teknik analisis data menggunakan korelasi Product moment. Hasil penelitian ini menunjukkan bahwa pembelajaran akhlak Aqeedah di MTs Ikhsaniyah Banyumudal Moga termasuk dalam kategori sedang dengan nilai rata-rata 50,6. Nilai ini berada dalam interval 45.2-56. Sedangkan variabel Semangat Nasionalisme Siswa MTs Ikhsaniyah Siswa Banyumudal Moga termasuk dalam kategori sedang, dimana hasil perhitungan diperoleh nilai rata-rata Jiwa Nasionalisme sebesar 58,03. Nilai ini berada dalam interval 53.74 - 63.34. Hasil perhitungan hubungan antara Aqeedah Moral Learning dengan Jiwa Nasionalisme Siswa MTs Ikhsaniyah Banyumudal Moga diperoleh koefisien korelasi sebesar 0,428. Selain itu, juga diperoleh hasil bahwa nilai signifikansi 0,000. Jika nilai signifikansi dibandingkan dengan tingkat signifikansi $(\alpha)$, nilai signifikansi yang diperoleh $=0,000<\alpha=0,05$. Dengan demikian dapat disimpulkan bahwa hipotesis nol (Ho) ditolak dan hipotesis alternatif (Ha) diterima. Dapat dikatakan bahwa ada hubungan positif yang signifikan antara Pembelajaran Moral Aqeedah dan Jiwa Nasionalisme Siswa. Koefisien korelasi 0,4288 berada pada interval 0,40-0,599 sehingga berdasarkan tabel tingkat korelasi dan kekuatan hubungan dapat disimpulkan bahwa hubungan antara pembelajaran moralitas dengan Jiwa Nasionalisme Siswa memiliki hubungan yang kuat.

Kata kunci: Belajar Aqidah Akhlak, Jiwa Nasionalisme Mahasiswa

\section{A. PENDAHULUAN}

Pembelajaran merupakan suatu proses yang kompleks dan melibatkan berbagai aspek yang saling berkaitan. Oleh karena itu, untuk menciptakan pembelajaran yang kreatif, dan menyenangkan, diperlukan berbagai keterampilan, diantaranya adalah keterampilan membelajarkan atau keterampilan mengajar. ${ }^{1} \quad$ Sehingga dalam hal ini pendidik haruslah terampil dalam mentransfer ilmu kepada anak didiknya. pembelajaran merupakan usaha sadar dan sengaja yang dilakukan secara sistematis untuk

1 E. Mulyasa, menjadi Guru Professional,(Bandung; Remaja Rosda Karya, 2005) Hlm.69 mencapai tujuan tertentu sesuai dengan tujuan pendidikan.

Hasan menyatakan bahwa Aqidah bermana simpulan, yakni kepercayaan yang tersimpul di hati. Aqidah secara bahasa ialah sesuatu yang dipegang teguh dan terhunjam kuat di dalam lubuk jiwa dan tak dapat beralih dari padanya. ${ }^{2}$ Menurut kamus Bahasa Indonesia, Aqidah memiliki arti keyakinan dasar atau keyainan pokok. ${ }^{3}$

Menurut istilah, aqidah dapat

\footnotetext{
${ }^{2}$ Galuh Nasrullah Kartika Mayangsari R, "Pendidikan Aqidah Dalam Perspektif Hadits", (Palangkaraya:Jurnal Transformatif (Islamic studies), Vol.1, No.1, 2017), hlm. 50 ${ }^{3}$ Hasan Ali, “Kamus Besar...”. hlm. 21
} 200 
diartikan sebagai konsep dasar tentang sesuatu yang harus diyakini, mengikat ('aqada) dan menentukan ekspresi yang lain dalam pengahayatan agama. Dengan demikian secara etimologis, aqidah berati kepercayaan atau keyakinan yang benar- benar menetap dan melekat dala hati manusia.

Pelajaran Aqidah Akhlak menekankan pada kemampuan memahami keimanan dan keyakinan Islam sehingga memiliki keyakinan yang kokoh dan mampu mempertahankan keyakinan/ keimananannya serta menghayati dan mengamalkan nilai- nilai Asmaul husna. Secara substansial pelajaran Aqidah Akhlak memiliki kontribusi dalam memberikan motivasi kepada peserta didik untuk mempelajari dan mempraktikkan akidahnya dalam bentuk pembiasaan untuk melakukan akhlak terpuji dan menghindari akhlak tercela dalam kehidupan sehari- hari. Aqidah Akhlak juga dapat mewujudkan manusia Indonesia yang berakhlak mulia dan mengindari akhlak tercela dalam kehidupan sehari- hari baik dalam kehidupan individu maupun sosial sebagai manifestasi dari ajaran dan nilai aqidah Islam. ${ }^{4}$

Dalam agama Islam telah diajarkan kepada semua pemeluknya agar dirinya menjadi manusia yang berguna bagi dirinya serta berguna bagi orang lain. Nasionalisme muncul dan berkembang menjadi paham yang

\footnotetext{
${ }^{4}$ Burhanudin Ilyas, Peran mata pelajaran Aqidah akhlak dalam menanamkan nilai pendidikan karakter siswa kelas $v$ (studi kasus di MIN kebonangun imogiri Bantul), skripsi sarjana FITK UIN Sunan Kalijaga yogyakarta (2013) hlm 16-17
}

dijadikan sebagai landasan hidup bernegara, bermasyarakat, dan berbudaya dipengaruhi oleh kondisi histori dan dinamika sosiokultural yang ada di masing- masing negara. ${ }^{5}$ Dalam kondisi yang memprihatinkan ini, kita sebagai bangsa yang berdaulat sejatinya memiliki kesadaran pribadi untuk membangun perubahan dan gerakan yang bisa memberikan semangat pantang mundur kepada kader- kader bangsa demi perbaikan dan kemajuan bangsa yang kita cintai. ${ }^{6}$ Dalam proses pembelajaran Aqidah akhlak di MTs Ikhsaniyah Banyumudal Moga Pemalang, terdapat pembelajaran tentang materi nasionalisme dan penerapannya dan dibuktikan dengan akhlak dalam kehidupan sehari- hari. Selain dari tuntutan kurikulum 2013 yang sudah diterapkan, para guru juga sedikit menyisipkan pendidikan nasionalisme saat kegiatan belajar mengajar berlangsung. Para guru mennyisipkan nilai- nilai nasionalisme pada siswa di MTs Ihsaniyah Banyumudal Moga melalui silabus yang diintegrasikan dengan nilai nasionalisme. Penanaman tersebut melalui upacara bendera setiap hari senin memperingati hari besar nasional, ekstrakulikuler, kemudian menghias dinding sekolah dengan tema nasionalisme. $^{7}$

\footnotetext{
${ }^{5}$ Ahmad hamdhani haqi, Nasionalisme bung karno dalam perspektif pendidikan Islam , skripsi sarjana FITK IAIN walisongo semarang (2013) Hlm 12 ${ }^{6}$ Mohammad takdir illahi,Nasionalisme dalam bingkai pluralitas bangsa, (yogyakarta:ar-ruzz media, 2012) Hlm 42

${ }^{7}$ Hasil observasi pada tanggal 06 mei 2018 pukul 09.00
} 
Dalam penelitian ini digunakan beberapa referensi untuk menghasilkan sebuah karya ilmiah, selama proses pembuatan penelitian ini, telah ditemukan beberapa skripsi dan bukubuku yang relevan dan untuk menghindari salah pengertian atau penafsiran dari judul skripsi ini, maka perlu dijelaskan mengenai istilahistilah dari judul yang di maksud yaitu:

a) Pembelajaran Aqidah Akhlak. Menurut Corey didalam buku Syaiful sagala, pembelajaran adalah suatu proses dimana lingkungan seseorang secara sengaja dikelola untuk memungkinkan turut serta dalam tingkah laku dalam kondisi khusus atau menghasilkan respon terhadap sitiuasi tertentu. $^{8}$

Pembelajaran berasal dari kata belajar. yang memiliki arti berusaha memperoleh kepandaian atau ilmu. Kata belajar mendapat imbuhan pe-an Jadi pembelajaran berarti proses, cara, perbuatan untuk menjadikan orang atau makhluk hidup belajar. ${ }^{9}$

Belajar merupakan suatu kegiatan yang berproses dan merupakan unsur yang sangat fundamental dalam menyelenggarakan setiap jenis dan jenjang pendidikan. Ini berarti, bahwa berhasil atau gagalnya pencapaian tujuan pendidikan itu amat tergantung pada proses belajar yang dialami oleh siswa baik ketika ia berada di sekolah maupun lingkungan rumah atau

\footnotetext{
${ }^{8}$ Syaiful sagala, Konsep dan Makna Pembelajaran, (Bandung: Alfabeta, 2005), hlm. 61

${ }^{9}$ Hasan Ali, Kamus Besar Bahasa Indoneia, (Jakarta: Balai pustaka, 2000), hlm. 17
}

keluarganya sendiri. $^{10}$ Aunurrahman menjelaskan bahwa pembelajaran diartikan sebagai suatu sistem yang bertujuan untuk membentu proses belajar peserta didik, yang berisi serangkaian peristiwa yang dirancang, disusun sedemikian rupa untuk mendukung dan mempengaruhi terjadinya proses belajar yang bersifat internal. ${ }^{11}$

Pembelajaran ada karena terdapat sebuah proses interaksi, komunikasi antara peserta didik dan pendidik. Interaksinya dapat berupa bantuan yang diberikan oleh pendidik kepada peserta didik.

Akidah menurut bahasa berasal dari bahasa arab "Aqdan" berarti simpul, ikatan, perjanjian yang kokoh. Sedangkan akidah berarti keyakinan dan kata akidah berakar dari kata 'aqada-ya'qidu- 'aqdan-aqidatan.

Relevansinya anatara kata 'aqada dan "aqidah adalah keyakinan itu tersimpul dengan kokoh didalam hati, bersifat mengikat dan mengandung perjanjian.

Sedangkan akhlak secara bahasa berasal dari bahasa arab berbentuk jama' dari 'khuluq yang berarti budi pekerti, perangai, tingkah laku, atau tabiat. Berakar dari kata khalaqa yang berarti menciptakan. Seakar dengan kata Kholiq (pencipta), makhluq (yang diciptakan), Khalaq (penciptaan). ${ }^{12}$ Akhlak adalah suatu keadaan yang melekat pada jiwa manusia yang

\footnotetext{
${ }^{10}$ Muhibbin syah, psikologi belajar,(Jakarta: Logos Wacana Ilmu,2001) hlm. 59

${ }^{11}$ Aunurrahman, Belajar dan Pembelajaran, (Bandung: Alfabeta, 2009), hlm.34

${ }^{12}$ Yunahar Ilyas, Kuliah Aqidah Islam, (Yogyakarta: LPPI, 2005), hlm. 1
} 202 
daripadanya lahir perbuatan- perbuatan dengan mudah, tanpa melalui proses pemikiran, pertimbangan, atau penelitian. Jika keadaan (hal) tersebut melahirkan perbuatan yang baik dan terpuji menurut pandangan akal dan syarak (hukum Islam), disebut akhlak yang baik. Jika perbuatan- perbuatan yang timbul itu tidak baik, dinamakan akhlak yang buruk. ${ }^{13}$

Aqidah akhlak adalah upaya menyiapkan peserta didik untuk mengenal, memahami, menghayati dan mengimani Allah SWT dan merealisasikannya dalam perilaku atau budi pekerti mulia.

Setelah mengetahui definisi dari beberapa kata diatas , jadi pengertian pembelajaran akidah akhlak adalah upaya sadar dan terencana dalam menyiapkan peserta didik untuk mengenal, memahami, menghayati, dan mengimani Allah SWT. Dan merealisasikannya dalam perilaku mulia dalam kehidupan sehari- hari melalui kegiatan bimbingan, pengajaran, latihan, penggunaan, pengalaman, dan pembiasaan. ${ }^{14}$

Menurut Ki Hajar Dewantara sebagaimana dikutip oleh Bimo Walgito, jiwa diartikan sebagai : Kekuatan yang menyebabkan hidupnya manusia, Serta menyebabkan manusia dapat berpikir, berperasaan dan berkehendak, Lagi pula menyebabkan

${ }^{13}$ Dewan Redaksi Ensiklopedi Islam, Ensiklopedi Islam, (Jakarta: PT Ikrar Mandiriabadi, 2002) hlm. 102

${ }^{14}$ Depag RI, kurikulum Madrasah Tsanawiyah (standar kompetensi), (jakarta: Direktorat jenderal kelembagaan agama Islam, 2004), hlm. 22 orang mengerti atau insyaf akan segala gerak jiwanya. ${ }^{15}$

Nasionalisme berasal dari kata nation yang berarti bangsa. Menurut Kamus Besar Bahasa Indonesia, kata bangsa memiliki arti : (1) kelompok masyarakat yang bersamaan asal keturunan, adat, bahasa, dan sejarahnya. (2) golongan manusia, binatang, atau tumbuh-tumbuhan yang mempunyai asal usul dan sifat khas yang sama (4) kedudukan mulia (3) kumpulan manusia yang biasanya terikat karena kesatuan bahasa dan kebudayaan dalam arti umum, dan menempati wilayah tertentu di muka bumi. ${ }^{16}$ Beberapa makna kata bangsa diatas menunjukkan arti bahwa bangsa adalah kesatuan yang timbul dari kesamaan keturunan, budaya, pemerintahan, dan tempat. Pengertian ini berkaitan dengan arti kata "suku" yang dalam kamus yang sama diartikan sebagai golongan orang-orang (keluarga) yang seturunan, golongan bangsa sebagai bagian dari bangsa yang besar. ${ }^{17}$ Sedangkan Nasionalisme menurut Ubed abdillah dalam bukunya, nasionalisme adalah sebuah ideologi sekaligus merupakan suatu bentuk dari tingkah laku. Sulit membedakan keduanya karena tingkah laku itu sendiri bisa menjadi bagian dari ideologi. ${ }^{18}$

Dalam perspektif Islam, ada dua kata yang biasanya dikaitkan dengan

${ }^{15}$ Bimo walgito, Pengantar Psikologi Umum, (Yogyakarta: CV Andi offset, 2005), hlm.6

${ }^{16}$ Hasan Ali, ..... hlm. 775

${ }^{17}$ Ibid., hlm.970

${ }^{18}$ Ubed Abdillah, Politik identitas etnis, Pergulatan tanda tanpa identitas, (Magelang: Indonesia tera, 2002), hlm. 85 
ide nasionalisme; al-Wathaniyah dan al-Qawmiyah. Menurut al-banna, pengertian dua kata tersebut dalam konteks kebangsaan adalah bahwa alwathaniyah sepadan dengan kata patriotisme yang berarti rasa cinta tanah air. Konsep ini merujuk pada ruang tertentu, tempat tinggal dan tanah tumpah darah. Keterikatan pada identitas bersifat given atau dalam teori sosiologi sebagai status yang diperoleh (ascribed status). Singkatnya adalah rasa memiliki negeri sendiri. ${ }^{19}$ Adapun kata al-Qawmiyah berarti rasa berbangsa dan bernegara , rasa memiliki kesatuan masyarakat politik yang dicapai dan diraih melalui perjuangan tertentu. Konsep ini mengacu pada orang atau sekelompok orang, biasanya disatukan oleh satu ideologi, visi, dan aspirasi tertentu untuk mencapai tujuan bersama. ${ }^{20}$

Jadi dapat dikatakan bahwa jiwa nasionalisme adalah situasi kejiwaan dimana kesetiaan seseorang secara total akan diabdikan langsung kepada negara atas nama sebuah bangsa. ${ }^{21}$

Indonesia has a very ideal and outstanding philosophy in the nation and state indeed, i.e. Pancasila. However, the meaning and implementation are often interpreted, construed, and practiced partially, merely to justify the momentary interests that are far from the values of

\footnotetext{
${ }^{19}$ Abdul hamid Al-Ghazali, Peta Pemikiran Hasan Al-Banna:Meretas jalan kebangkitan Islam,(Solo: Era Intermedia, 2001), hlm 195

${ }^{20}$ Ibid., hlm. 198

${ }^{21}$ Setyamecca.blogspot.com/2014/06/ makalah/nasionalisme-indonesia.html? $\mathrm{m}=1$ diakses pada tanggal 19 november 2018 pukul 08.48
}

the state and nation. In line with the diversity in the framework of Bhineka Tunggal Ika realized, mental revolution is a basic character that should be strengthened, given its presence can unite differences, such as the differences in ethnicity, religion, race, culture, ideology and custom. ${ }^{22}$

\section{B. METODE PENELITIAN 1. Jenis dan Pendekatan Penelitian}

Jenis penelitian ini berupa penelitian lapangan (field research) dengan menggunakan pendekatan kuantitatif.Tehnik pengumpulan data penelitian ini adalah metode angket dan metode dokumentasi.Tehnik analisis data menggunakan korelasi Product moment.

\section{Tempat dan Waktu Penelitian}

Penelitian ini dilaksanakan di MTs Ikhsaniyah Banyumudal Moga tahun ajaran 2018/2019 tepatnya di Jl. Raya Moga - Pulosari Km 0,5 Banyumudal Moga Pemalang. Adapun pelaksanaan penelitian ini dimulai dari bulan Februari sampai dengan bulan Agustus 2019.

\section{Populasi dan Sampel}

Populasi dalam penelitian ini adalah seluruh siswa kelas MTs Ikhsaniyah banyumudal Moga pada tahun pelajaran 2018/2019 yang berjumlah 560 siswa.Berdasarkan pendapat di atas, maka dalam penelitian ini hanya mengambil $15 \%$

\footnotetext{
${ }^{22}$ Muhlisin,"Mental Revolution Through ReligiousAnd Character Education In Primary And Secondary Education", (Pekalongan ;Realizing mental revolution through reconstruction of science in Islamic higher education instituion, Part II : Education Two: Educational Management and Character Education, 2016), hlm.238
} 
dari keseluruhan populasi tersebut, dengan 80 siswa sebagai sampelnya.

\section{Variabel Penelitian}

Pada penelitian terdapat dua variabel, yaitu variabel bebas (pembelajaran aqidah akhlak) dan variabel terikat (Jiwa Nasionalisme Siswa)

a) Variabel Independen (Pembelajaran Aqidah akhlak) terdapat variabel independen $(\mathrm{X})$ dalam penelitian yaitu pembelajaran Aqidah akhlak. Adapun aspek-aspeknya yaitu :

1) Tujuan Pembelajaran Aqidah Akhlak.

2) Metode pembelajaran yang digunakan guru Mata pelajaran Aqidah akhlak.

3) Sistem evaluasi pembelajaran Mata pelajaran Aqidah akhlak.

b) Variabel Dependen (Jiwa nasionalisme)

Variabel dependen (Y) dalam penelitian ini adalah jiwa nasionalisme siswa. Adapun indikator untuk mengukur Jiwa nasionalisme siswa, penulis menggunakan pendapatmoeljonoYaitu :

1) Rela Berkorban.

2) Persatuan dan Kesatuan.

3) Harga Menghargai.

4) Kerjasama.

5) Kecintaan Terhadap Tanah Air. ${ }^{23}$

\section{Teknik dan \\ Instrumen}

Pegumpulan Data

Untuk memperoleh data yang objektif dan valid, dalam penelitian ini

${ }^{23}$ Moeljono Djojomartono. Jiwa Semangat dan Nilai-Nilai Perjuangan Bangsa Indonesia.(Semarang: IKIP Press.1989). HIm. 5 penulis menggunakan beberapa teknik pengumpulan data, antara lain:
a. Metode Angket
b. Metode Dokumentasi

\section{PEMBAHASAN \\ 1. Deskripsi Hasil Penelitian}

Berdasarkan hasil analisis data pada variabel Pembelajaran Aqidah akhlak, diketahui bahwa Pembelajaran Aqidah akhlakdi MTs Ikhsaniyah Banyumudal Moga termasuk dalam kategori sedang. Dimana diperoleh hasil perhitungan nilai rata-rata Pembelajaran Aqidah akhlak di MTs Ikhsaniyah Banyumudal Moga sebesar 50,6. Nilai tersebut masuk dalam kategori sedang yang mana kategori sedang berada pada interval 45,2 - 56 .

Berdasarkan hasil analisis data diketahui bahwa Jiwa Nasionalisme Siswa MTs Ikhsaniyah Banyumudal Moga termasuk dalam kategori sedang, dimana diperoleh hasil perhitungan nilai rata-rata prestasi belajar Pendidikan Agama Islam sebesar 58,03. Nilai tersebut berada pada interval 53,74-63,34.

Hasil perhitungan hubungan antara Pembelajaran Aqidah akhlak dengan Jiwa Nasionalisme Siswa MTs Ikhsaniyah Banyumudal Moga diperoleh koefisien korelasi sebesar 0,428.Selain itu, juga diperoleh hasil bahwa nilai signifikansi sebesar 0,000 . Apabila nilai signifikansi tersebut dibandingan dengan taraf signifikansi ( $\alpha$ ) maka diperoleh nilai signifikansi $=$ $0,000<\alpha=0.05$. Dengan demikian dapat disimpulkan bahwa hipotesis nol (Ho) ditolak dan hipotesis alternatif (Ha) diterima. Dapat dikatakan terdapat 
hubungan positif yang signifikan antara Pembelajaran Aqidah Akhlak dengan Jiwa Nasionalisme Siswa. Dimana koefisien korelasi sebesar 0.4288 berada pada interval 0,40-0,599 sehingga berdasarkan tabel tingkat korelasi dan kekuatan hubungan dapat disimpulkan bahwa hubungan antara Pembelajaran Aqidah akhlak dengan Jiwa Nasionalisme Siswa memiliki hubungan yang kuat.

Kemudian hasil perhitungan koefisien determinasi kecerdasan spiritual menunjukkan bahwa sumbangan pembelajaran aqidah akhlak adalah sebesar R Square $=35 \%$ terhadap jiwa nasionalisme siswa MTs Ikhsaniyah Banyumudal Moga, dengan demikian sumbangan pembelajaran aqidah akhlak terhadap jiwa nasionalisme siswa sangat bermakna, artinya $35 \%$ jiwa nasionalisme siswa dipengaruhi oleh pembelajaran aqidah akhlak dan selebihnya dipengaruhi oleh faktor lain.

\section{DAFTAR PUSTAKA}

Abdillah, Ubed, Politik Identitas Etnis, Pergulatan Tanda Tanpa Identitas. Magelang. Indonesia Tera, 2002.

Ali,Hasan. 2000. Kamus Besar Bahasa Indoneia. Jakarta. Balai pustaka.

Aunurrahman, Belajar dan Pembelajaran. Bandung. Alfabeta, 2009.

Depag RI, Kurikulum Madrasah Tsanawiyah Kompetensi). (Standar Direktorat jenderal kelembagaan agama Islam, 2004.

Dewan Redaksi Ensiklopedi Islam, Ensiklopedi Islam. Jakarta. PT Ikrar Mandiriabadi, 2002.

Muhlisin, Mental Revolution Through ReligiousAnd Character Education In Primary And Secondary Education", dalam Paper Realizing mental revolution through reconstruction of science in Islamic higher education instituion, Part II : Education Two: Educational Management and Character Education. Pekalongan, 2016.

Mulyasa, Menjadi Guru Professional. Bandung. Remaja Rosda Karya, 2005.

Syah, Muhibbin, Psikologi belajar. Jakarta. Logos Wacana Ilmu, 2001.

Takdir illahi, Mohammad, Nasionalisme dalam Bingkai Pluralitas Bangsa. Yogyakarta. Ar-ruzz media, 2012.

Walgito Bimo, Pengantar Psikologi Umum.Yogyakarta. CV Andi offset, 2005. 